\title{
Resolving semantically induced tip-of-the-tongue states for proper nouns
}

\author{
TIM BRENNEN, THOM BAGULEY, JIM BRIGHT, and VICKI BRUCE \\ University of Nottingham, Nottingham, England
}

\begin{abstract}
Three experiments are reported in which tip-of-the-tongue states (TOTSs) were induced in subjects by reading them pieces of item-specific information. In Experiments 1 and 2, subjects attempted to name famous people. These experiments showed that, in a TOTS, seeing a picture of the face of the target person did not facilitate naming, whereas the initials of the person's name did. In Experiment 3, a similar result was obtained with a landmark-naming task. The results of the experiments are discussed with reference to current models of memory structure and name retrieval.
\end{abstract}

The tip-of-the-tongue state (TOTS) is an everyday phenomenon. When one attempts to recall a particular word or name, one experiences some degree of partial knowledge, along with a feeling that one could recognize the "target." William James (1893) was prompted to describe this state as "a sort of wraith of a name."

The first quantitative study of the TOTS was conducted by Brown and McNeill (1966). They provided evidence as to the nature of the partial knowledge that is available in TOTSs. Successful guessing of the number of syllables in the target word was achieved in a high proportion of cases, and, even more impressively, because of the lower chance levels, a word's initial letter was offered correctly on $57 \%$ of the occasions.

Yarmey (1973) first drew attention to the occurrence of TOTSs in other naming tasks--specifically, in person naming. He presented faces of famous people to subjects, their task being to name the people. The information that the subjects were able to report when they were in TOTSs was categorized: The most reported information involved the person's profession, and where the person had last been encountered. But Yarmey also noted that phonemic information, such as the number of syllables, initial letters, and so forth, was often present and highly accurate. He concluded that although the target in a name search is a verbal representation, other more perceptual retrieval systems are also involved in retrieving the to-beremembered name.

More recently, TOTSs have been investigated in everyday situations. Reason and Lucas (1984), who asked subjects to keep diaries of naturally occurring TOTSs, reported that both common and proper names provoked

\footnotetext{
This study was supported by ESRC Studentship C00428625014 to Tim Brennen and ESRC Project Grant XC15250001 to Vicki Bruce. We are grateful to Andy Young, Dibs Hellawell, and the referees for helpful comments on earlier drafts. Please send reprint requests to Tim Brennen, Department of Psychology, University of Nottingham, University Park, Nottingham NG7 2RD, U.K.
}

TOTSs, but that the latter predominated. Cohen and Faulkner (1986) reported a diary study of "name blocks" for proper names specifically, in which subjects were asked to give extensive details each time a block was experienced. They found that the majority of name blocks occurred for names of friends and acquaintances.

Recent work by Hanley and Cowell (1988) used a TOTS-inducing procedure to investigate $\mathrm{V}$. Bruce and Young's (1986) functional model of face recognition, by comparing cue utilities for accessing person-specific information and name codes. The V. Bruce and Young model deals with the types of processing that can occur upon seeing a face, such as expression analysis, semantic attributions, and so forth. Of importance for the present study is the set of cognitive processes that are typically involved when one attempts to retrieve the name of a familiar face. Following a suggestion made by Hay and Young (1982), V. Bruce and Young (1986) propose that there is a sequence of distinct stages that occur when one sees a familiar face. There is an initial structural encoding stage, from which face-centered representations emerge. These representations are then compared with the sets of structural codes stored at the face recognition unit (FRU) level. It is proposed that such a recognition unit exists for each familiar face, and that if the input is sufficiently similar to one of the structural codes held in the recognition units, then that recognition unit is activated. When the FRU has fired, the face is confirmable as familiar. The knowledge that one has of that particular person is deemed to be stored at a specific person identity node (PIN), which may then be accessed to yield such information.

For both logical and empirical reasons, V. Bruce and Young (1986) proposed that the name code is the final one to be accessible and indeed can be accessed only via the PINs. Not least of the reasons for this proposal was the observation that, in an extensive diary study of slips in person identification, it was never the case that the name of a person was reportable unless semantic information also was available (Young, Hay, \& Ellis, 1985). 
Experimental evidence on this point was provided by Young and colleagues (Young, McWeeny, Ellis, \& Hay, 1986; Young, McWeeny, Hay, \& Ellis, 1986), who showed that even when a small, overlearned set of faces is used, subjects are quicker to categorize the stimuli than to name them. When the response requirements were equated, so that both the naming and the categorizing tasks involved a binary decision, the categorization judgments remained quicker. These results provide further support for the V. Bruce and Young (1986) claim that the name code is only accessible after the PINs.

Hanley and Cowell (1988) presented subjects with a series of faces and required them to decide whether or not each face was familiar, and, for familiar faces, further to recall the person's occupation and name. On the basis of the V. Bruce and Young model, there were thus four possible "knowledge states" that were expected to arise for familiar faces; namely, (1) face found unfamiliar, (2) face found familiar but occupation not reported, (3) face found familiar, occupation known but name not reported, and (4) all person-specific information available, including the person's name. Three types of cue were used when subjects were in States 1, 2, or 3: (1) a second photograph of the target person, (2) person-specific information, and (3) structural information about the name (the initials and name length of the target person, presented with the fragmented names of three other semantically similar, and therefore confusable, persons).

Drawing on the V. Bruce and Young (1986) model, Hanley and Cowell (1988) were able to predict a specific interaction between the efficacy with which each cue allowed name retrieval and the knowledge state. A second photograph of the target person was predicted to be ineffective as a cue for name retrieval if the subject had initially found the face familiar, since the FRU for that person must already have been accessed. If the first face was deemed unfamiliar, however, a second view of the face could allow access to the FRU for the target person. The person-specific information was predicted to be most useful when the subject found the face familiar but was unable to report the occupation of the person in question. In this case, the person-specific information could allow access to the PIN. Finally, the name-structure cue would be expected to provide the most facilitation when the subject was in a classic TOTS, both judging the face familiar and knowing the person's occupation concurrent with a feeling of knowing, without being able to access the name. Taking together the results of Hanley and Cowell's two experiments, the model's predictions were largely borne out.

An aspect of the V. Bruce and Young (1986) model that is crucial in this context is that the PINs are deemed to be the stage at which the different routes to person identification converge. For example, perception of voice or gait, or presentation of person-specific information can all allow access to the PINs. Hence TOTSs could arise after access to the PIN from any route to person identification: A TOTS is simply a manifestation of successful access to the PIN, but a failure to access the name code. Thus the model affords further investigation within a TOTS paradigm.

In this study, we will adopt a design akin to Hanley and Cowell's (1988), in order to investigate whether the V. Bruce and Young (1986) model is similarly successful in accounting for differential cue utilities for resolving TOTSs that have been induced by person-specific information, rather than by the presentation of faces. This semantically induced type of TOTS is akin to that which arises when one plays popular general knowledge quiz games, such as Trivial Pursuit. For example, upon being asked, "Who plays Blake Carrington in 'Dynasty'?" we may be sure that we know the answer but may be temporarily unable to retrieve the name of the person (John Forsythe).

Specifically, we test whether semantically induced TOTSs are reliably relieved by presentation of the face of the person in question. Interestingly, in this regard, Cohen and Faulkner (1986) report that their diarists claimed that name blocks occurred more often when they tried to think or to communicate about a person than when the person was physically present, and so it might be expected that seeing a picture of the face of the target person would reliably aid name retrieval in TOTSs.

Another reason why the hypothesis seems plausible comes from data reported by Read and D. Bruce (1982). They used pieces of information about people to generate name blocks, and investigated the time course of retrieval of such names over the course of a 10-week period. Blocking on names was induced by either a picture of the person's face, or a verbal description of the person. When a subject blocked on a name, and had failed to retrieve it by the following experimental session, the subject was then presented either with the same cue (same cue condition) or with the other one (alternating cue condition). Read and D. Bruce found that name recall in the alternating cue condition was facilitated relative to the same cue condition. Another important aspect of Read and D. Bruce's work is that, when accounting for successful retrieval of a person's name after an information-induced name block, some of their subjects reported that an image of the face of the person flashed into their minds, thus allowing them to retrieve the name.

These initial suggestions from the literature are important, because the current formulation of the V. Bruce and Young (1986) model has no ability to account for facilitation from such a pictorial cue. The model unequivocally predicts that access to the same PIN by a second route will not be useful in resolving a TOTS, so that in this case, a TOTS should not be aided by presentation of a picture of the target person. Presentation of the face would activate the FRU in question and thus also provide access to the PIN, but the model considers that the identity-specific semantics have already been accessed and predicts no naming facilitation.

An alternate explanation for any naming facilitation upon seeing the face would be that there is a direct route 
from an earlier stage of face processing (e.g., FRU level) to the name code. However, within the V. Bruce and Young (1986) framework, no such direct route exists for face recognition. Similarly, for object recognition, there is no clear evidence that such a route exists (Ratcliffe \& Newcombe, 1982).

In fact, the apparently problematic findings of Cohen and Faulkner (1986) and Read and D. Bruce (1982) are less conclusive than they may appear. Cohen and Faulkner (1986) reported that their subjects claimed more nameretrieval difficulty for the names of people who were absent than for the names of people who were present. However, this present/absent difference may be confounded with familiarity, and furthermore, the baseline levels of name blocking are unknown: It may be that the retrieval of names is attempted more for absent people than for present people. Read and D. Bruce (1982), on the other hand, do not present data for the crucial condition in which subjects are in a semantically induced TOTS that is resolved by the face of the person in question. In their study, the subjects had to rate the retrievability of the target names. From the description of their data, it appears that the alternating cue condition was facilitatory only when the rated retrievability of the target name was low (i.e., when subjects were not in a TOTS). In terms of the V. Bruce and Young (1986) model, if the PIN of the person has not been accessed, then a face cue would be expected to facilitate naming. Because the V. Bruce and Young model makes the very clear prediction that a face should not help resolve a semantically induced TOTS, it is important to reexamine the issue.

There are other issues that the present study will address. One involves the matter of whether semantic information is stored in a modality-specific or in a general form. If the sequence of identity-processing modules described in the V. Bruce and Young (1986) model is largely correct, and if semantic information is stored but once (as is the case in the V. Bruce and Young model) when a subject is in a TOTS, the providing of a cue of a modality different from that by which the state was originally induced should not facilitate resolution of the state. If, on the other hand, semantic memory is arranged in a modality-specific manner (see, e.g., Shallice, 1988), then TOTSs would also be modality-specific. In this case it would be expected that TOTSs would be resolved by presentation of a cue from a modality different from that which originally induced the TOTS. This expectation arises because the second cue would provide an alternative route to the name, via the semantics associated with the cue's modality.

Similarly, the present study is of relevance to the episodically based headed records theory of memory proposed by Morton, Hammersley, and Bekerian (1985). According to this model, memories for individual events are stored in separate records. This means that any particular fact may be stored more than once, in different records. Access to a record occurs in an all-or-none manner, when the heading for that record is accessed; the contents of the headings themselves are not subject to communication. This model could account for TOTSs simply as a failure of the cognitive context to provide the correct heading for a record that contained the name of the person in question. In terms of the experiment outlined above, the model should presumably predict that, given a new input of information (in this case a face), more headings could be created, giving access to other records, and thus increasing the probability of successful retrieval of the name.

Thus, a number of theories could accommodate a finding of facilitation from faces following semantically induced TOTSs. Such facilitation could support direct links from faces to names, multimodal semantic representations, or the headed records framework. In contrast, the V. Bruce and Young (1986) framework predicts that no facilitation should occur. In the experiments that follow, we examine whether semantically induced TOTSs are resolved by presentation of a picture of the face of the target person. Hanley and Cowell (1988) pointed out a potential loophole in designs such as these: Naming facilitation may be due to the extra opportunity to retrieve the name rather than due to the cue per se. Thus, in this study, we have attempted to control for the spontaneous resolution of TOTSs that may occur: For half of the TOTSs reported by subjects in Experiment 1, the experimenter merely repeated the semantic information; for the other half of TOTSs, a picture of the face of the person was presented.

\section{EXPERIMENT 1}

\section{Method}

Subjects. Fifteen undergraduate students at the University of Nottingham volunteered to take part in Experiment 1. They were naive with respect to the hypotheses of the experiment.

Materials. Fifty black-and-white photographs of television celebrities were taken from Granada's Who's Who on TV and stuck on pieces of card for ease of presentation. The name of the appropriate celebrity was written on the back of each card. For each celebrity, a piece of information, in the form of a question, was written on the outside of an envelope. The questions, devised by the experimenters, were designed to be sufficiently accurate to uniquely specify the person to which they referred. The 50 items were selected, after some informal piloting, from a pool of about 70 suitable items (e.g. , "Who is the actor who played the 'Bionic Man'?" [Lee Majors]). A complete list of the materials may be found in Appendices $\mathrm{A}$ and $\mathrm{B}$.

Design. This within-subjects experiment was designed to compare the rates of successful TOTS resolution yielded by two conditions: (1) repeating the semantic information, and (2) presenting the face of the target person. For each subject, the two conditions were alternated, one half of the subjects having the face condition for the first TOTS and the other half having the repeat information condition. The TOTSs arose as a byproduct of a person-identification task, in which subjects attempted to name people on the basis of being given a single sentence of information for each one.

The order of presentation of the semantic questions was rerandomized for each subject. The two conditions were alternated within subjects for each TOTS arising, and so there was no balancing of the questions over the two conditions, which represents a potential confound. However, because of the random orders of questions for 
each subject, there is no reason to presume that any question was associated with any particular condition.

Procedure. The subjects were told that they would be asked to answer some questions in which a TV celebrity would be described, and they would have to supply the person's name. The questions were read out loud by the experimenter.

The subjects were asked to reply "I don't know" if, and only if, they were certain that they did not know who the target person was, in which case the trial was terminated and the next question asked. In the case of incorrect responses, or if $5 \mathrm{sec}$ elapsed with no answer forthcoming, a wrong answer was recorded, and the next question was asked. Similarly, if the name was immediately reported, the next question was asked.

The final possibility was that the subject would indicate that he or she felt sure about knowing the target person, but could not currently recall the name. For our purposes, when a subject reported such a state, a TOTS was recorded. Note that even if such a criterion appears less rigorous than, for instance, Yarmey's (1973) definition of a TOTS, this would be expected to work in favor of the face cue's being successful, and against the V. Bruce and Young (1986) model's predictions. It therefore seemed important to work with a definition of a TOTS that erred on the weaker side.

When TOTSs were reported, information from one of two potentially helpful conditions was presented: Either the question was repeated, or a picture of the face of the person in question was shown. The subject then had 5 more seconds in which to answer.

In all cases, the "correct" answer was defined as the surname of the target person. In practice, the subjects were usually able to report the first name correctly if the surname could be reported.

\section{Results and Discussion}

The mean number of TOTSs reported per subject was 10.5 from the 50 questions, ranging from 4 incidences to 22. The mean percentage of these TOTSs that were resolved was $14.6 \%$ in the repeating question condition, and $12.4 \%$ in the face condition. There is no indication from these data that the resolution of semantically induced TOTSs could be facilitated by the face of the target person. A sign test was performed, indicating for each subject which cue had been more useful in resolving TOTSs. There was no significant difference between the two conditions. Indeed, of the 11 subjects for whom one cue was more useful than the other, 6 were more often relieved after the original information was repeated and 5 after the face had been shown.

Thus, in Experiment 1, no evidence was found to show that the face of a person for whose name a subject was currently experiencing a TOTS facilitated access to the name reliably. This result is consistent with the $\mathrm{V}$. Bruce and Young (1986) model, and it confirms the suggestion that a TOTS is a manifestation of a problem of access to the name code from the PIN.

One problem with Experiment 1 arose from an administrative error, which meant that conditions were not alternated in a strict fashion for 4 subjects. In the light of this and the fact that the nonsignificant result might simply have indicated that the design was not a sensitive one (perhaps $5 \mathrm{sec}$ was too short for any information to be helpful), Experiment 2 was designed to incorporate another cue that would be expected to facilitate TOTS resolution reliably. Hanley and Cowell (1988) demonstrated that presenting subjects with the initials of a per- son for whom a TOTS was being experienced was useful. This seemed a likely means of testing the sensitivity of the design, while also seeking to replicate the main result of Experiment 1.

\section{EXPERIMENT 2}

\section{Method}

Subjects. The subjects were 30 volunteers from local schools and colleges. All were naive with respect to the hypotheses of the experiment, and none had taken part in Experiment 1.

Materials. Around half of the famous people used in Experiment 1 were also used in Experiment 2. Some of the clues were made more uniquely person-specific, and a selection of "new" famous people was obtained from Skinner's Who's Who on the Screen, making the total up to 50 clues. As before, the clues were on the back of envelopes, each of which contained a photo of a celebrity's face. (See Appendices B and C for full description of the questions.)

Design. Each subject experienced a different random presentation of the 50 questions. If a TOTS was reported $5 \mathrm{sec}$ after the question had been read, one of three conditions was presented: (1) the face of the person in question was presented for $5 \mathrm{sec}$; (2) the person's initials were presented; (3) the original information was repeated. Within subjects, there was a strict rotation of cue presentation for each TOTS that was induced. This meant that for any subject the number of times the most used condition type occurred was never more than one higher than that for the least used condition type.

Procedure. Apart from the inclusion of the initials condition, the procedure was all but identical to that of Experiment 1. Additionally, the partial knowledge that subjects spontaneously reported during each TOTS was recorded in this experiment.

\section{Results}

The mean number of TOTSs yielded by each subject was 8.5 ; the range was $1-15$. The modal number of TOTs reported was 8 . The mean percentage of instances for which the name in question was successfully retrieved within $5 \mathrm{sec}$ of cue presentation was $10.7 \%$ in the repeat condition, $14.5 \%$ in the face condition, and $46.6 \%$ in the initials condition. Using a Friedman two-way analysis of variance ranks test, it was shown that there was a reliable effect of cue type upon probability of successful name retrieval in a TOTS $\left[\chi^{2}(2)=14.32, p<.01\right]$. Since the mean ranks for the face and repetition cues were very similar (at 1.8 and 1.6, respectively), the overall significant effect is due to the facilitation provided by the initials cue.

This was confirmed by sign tests comparing each of the conditions with the control condition. Initials were significantly better than repetition for 21 out of 22 subjects for whom there was not a tie between the two conditions' resolution rates $(p<.05)$. There was no advantage for faces over repetition, however, with only 9 of 15 untied observations favoring the face condition.

The qualitative data provided by subjects while in a TOTS were also analyzed. From the 254 instances of TOTSs in this experiment, the various types of information were spontaneously given with the total frequencies shown in Table 1 . The figure in brackets is the percentage of occasions on which each was given. 
Table 1

Frequencies and Percentages for Types of Partial Information that Subjects Spontaneously Reported in Experiment 2

\begin{tabular}{lcc}
\hline Type of Information & Frequency & Percent \\
\hline Image of face & 67 & 26 \\
Physical appearance & 57 & 22 \\
Voice & 3 & 1 \\
Episodic information & 47 & 19 \\
\hline
\end{tabular}

\section{Discussion}

Even in a design shown to be suitably sensitive, the face cue was not facilitatory in resolving TOTSs. Furthermore, the percentage of occasions upon which either the face or the repeat condition successfully resolved a TOTS, $12.6 \%$, was very similar to that observed in Experiment 1 (13.5\%). Experiment 2 thus successfully replicated Experiment 1 ; this is nontrivial, because different subjects took part in the experiments and partially different materials were used.

It is worth noting that some instances of the name's being retrieved after presentation of the face may have resulted from what Brown and McNeill (1966) labeled "negative", TOTSs-that is, when the subject has reported a TOTS, but where it later transpires that the target person is different from the one about whom the subject was thinking. Thus the "correct" name may be immediately retrievable upon seeing the face in question. There is no doubt that such negative TOTSs did occur during the experiment, because subjects occasionally reported them upon being presented with the face (e.g., "Oh. That's not the one I was thinking of. That's Gareth Hunt' '). The possible confounding element arises from trials on which those negative TOTS are not reported. However, despite this possibility, no significant facilitation was observed with the face cue, as compared with the control condition.

The initials cue provided reliable resolution of the semantically induced TOTS. This is congruent with V. Bruce and Young's (1986) conceptualization of a TOTS as being a failure to access the name code while having accessed the PIN for the person in question. The only types of cue that would be expected to produce facilitation in such cases would be those providing structural information about the person's name. This is not to say, however, that all the facilitation provided by the initials cue arose as a result of the resolution of the TOTSs; it is possible that presenting the initials alone, pre-TOTS, would allow correct guessing on some occasions. But, bearing in mind the paucity of the initials information (cf. Hanley \& Cowell, 1988, who included name length too) and also the immediacy with which subjects often responded with the correct name after presentation of the initials cue, it seems reasonable to assume that the initials cue was provoking genuine resolution in the majority of cases. This suggestion was checked by asking a different group of 10 subjects to try to guess the identity of famous showbusiness people from their initials alone. The subjects found the task difficult and unrewarding: In under half of the occasions a plausible name was offered within the 5-sec time limit (which equated this procedure with that in Experiment 2), and a substantial proportion of these names were not the ones for whom the initials had been used in Experiment 2. The overall successful guessing rate emerged at $7 \%$, which is a small (and hence unimportant) proportion of the $46.6 \%$ success rate obtained when the subjects reported TOTSs.

Upon examination of the qualitative data obtained from the subjects about the accessible (partial) knowledge that they had during a TOTS, an explanation of the face cue's failure to provide facilitation emerges. In $26 \%$ of the TOTSs reported in Experiment 2, the subjects made spontaneous references to the fact that they were imaging the face of the target person, and in a further $22 \%$, information about the person's appearance was given. It is probable that the overall rate of face-imaging is higher than this: The instances mentioned here were those in which subjects made explicit references to the phenomenon. This suggests that being shown a picture of the face would be superfluous, and that it would not furnish a subject with additional information. This impression was supported by some subjects' comments upon being shown the face (e.g., "I know what he looks like-I can't remember his name'). This means that when access to the PIN has occurred, information about appearance is also usually available. Whether or not this has been obtained from the activation of input recognition units is an interesting topic for further research.

\section{GENERAL DISCUSSION OF EXPERIMENTS 1 AND 2}

In Experiment 1, there was no reliable difference in TOTS resolution rate between the repetition of the question and presentation of the face of the person in question. Experiment 2 consolidated this result by showing that there is a cue that is reliably able to resolve semantically induced TOTSs. This finding allows us to reject the hypothesis that there is no cue type that, when presented while the subject is in a TOTS, would reliably relieve it. Thus, the finding strengthens the conclusion that presentation of the face does not resolve a semantically induced TOTS. This outcome is an apparent contradiction of Read and D. Bruce's (1982) data, for which a different modality cue appeared to resolve name blocks. However, as pointed out earlier, their effect may be due to the facilitation provided when subjects had only a vague notion of who the person was. The data from our first two experiments are thus consistent with the V. Bruce and Young (1986) model of face recognition: Semantically induced TOTSs are not reliably relieved by presentation of the person's face. Although the V. Bruce and Young (1986) model deals specifically with face recognition, its broad architecture is akin to that proposed for the recognition of other stimuli too (see, e.g., Nelson, Reed, \& McEvoy, 1977). Since the issue of multimodal semantic systems has also been raised with object recognition in mind (e.g., see Shallice, 1988), it would be particularly interesting to pursue 
the above TOTS paradigm for objects too. To extend the task to object naming, however, requires some ingenuity.

It is important that the materials generate measurable numbers of TOTSs, but it is also important that subjects should recognize a visual picture of these materials. For instance, one of Brown and McNeill's (1966) descriptions was of a sextant. It seems quite plausible that subjects may find themselves in a TOTS for the word upon hearing a description of it, while not being able to recognize a picture of a sextant, because there is no visual memory for the object. If there was a high proportion of such cases, the conclusion that a picture of the object did not facilitate naming would not be interesting. This conceptual objection to the use of objects was compounded by the observation that it proved rather difficult to collect materials that would generate TOTSs using descriptions of objects. This difficulty appears to have been observed by other researchers too. For instance, Jones (1989), who gave verbal descriptions of words in order to induce TOTSs, used a very low proportion of concrete words, presumably because abstract words are more susceptible to TOTSs. This in fact tallies with Cohen and Faulkner's (1986) finding that TOTSs for proper nouns predominated in their diary study, presumably because common nouns can be substituted by circumlocutions.

To get around these problems, we decided to perform an experiment identical in design to Experiment 2, using famous landmarks and thus allowing us to investigate TOTSs for another class of proper nouns. Such materials provide a comparison between person naming and object naming, because in both tasks the subject has to make an intracategory discrimination rather than an intercategory one; to name the Golden Gate Bridge from a verbal description of it, for example, one has to discriminate between it and all other bridges. Similarly, subjects had to discriminate between Lee Majors and all other children's TV stars in the first experiment. Furthermore, we deemed that, as with person naming, the proportion of failures to recognize the visual stimulus given that the semantic information was familiar would be low.

\section{EXPERIMENT 3}

\section{Method}

Subjects. Thirty volunteers were used in Experiment 3. Ten of them came from local sixth form colleges and the remainder from the undergraduate population of Nottingham University. None had taken part in the first two experiments.

Materials. Pictures were culled from a variety of sources, including a children's encyclopedia, postcards, and travel brochures. Some landmarks, such as the Taj Mahal and the Eiffel Tower, were chosen to be highly familiar, in order to ensure that all subjects were able to retrieve the correct name occasionally, but most of them were less familiar than these. Pilot research showed that, by and large, the materials were in the suitable range of familiarity for subjects. (See Appendix D for the clues.)

When 40 appropriate pictures had been collected, semantic clues were written for each one. With landmarks, a potential problem arises because of the heterogeneity of their form (e.g., Ayers Rock vs. the Leaning Tower of Pisa), and so a full verbal description of them could largely constrain the type of imaging that could oc- cur; for example, if one described the Leaning Tower of Pisa as "The white marble tower in central Italy which leans at 13 degrees to the vertical," then to show that a picture of the tower did not relieve TOTSs might not be surprising. Thus, care was taken to avoid clues that overspecified the appearance of the landmark (e.g., "The marble building in Italy that is going to fall over by the year 2020 , it is said").

Design. This experiment had a design identical to that of Experiment 2. It was a one-factor within-subjects design, with three levels: control, in which the information was merely repeated; picture of the landmark; and the initials of the name. As with some of the famous persons' names in Experiment 2, some of the landmarks had names composed of multiple words, and so these names had initials cues that were more informative (e.g., Empire State Building).

Procedure. The subjects were tested individually, in a session that lasted approximately $10 \mathrm{~min}$. For each subject, a different order of landmark clues was used. As in Experiment 2, the three conditions were alternated between TOTSs, ensuring that no condition was used more than once more than any other, for any given subject. The descriptions were read out, and each subject's response recorded as before.

\section{Results and Discussion}

A total of 175 TOTSs was generated in this experiment, giving a mean of 5.8 per subject. The modal number was 5 per subject and the range of numbers of TOTSs generated was 2-10. The percentage of successful TOTS resolution over all subjects was $13.6 \%$ for the repeat condition, $22.0 \%$ for the picture condition, and $43.9 \%$ for the initials condition. A Friedman's two-way analysis of variance ranks test was performed on the data on the ranks of successful TOTS resolution for each condition across subjects. It showed that there were significant differences across the three conditions $\left[\chi^{2}(2)=10.87, p<.01\right]$. Sign tests were carried out for all three planned comparisons. For the initials versus control comparison, there were 17 subjects for whom one condition was more successful than the other, and in all cases the initials condition was more successful than the control condition; the initials cue was more successful than the picture condition for 16 of the 21 subjects for whom there was a difference $(p<.025)$. However, there was no significant difference between the picture and the control condition; 10 of 15 subjects were better in the picture than the control condition, with 15 ties $(p>.05)$.

Experiment 3 showed that the conclusion of the first two experiments generalizes to a stimulus domain other than person naming. Again, the initials cue reliably aided recall of names, whereas seeing a picture of the landmark did not aid resolution of the TOTSs. Furthermore, the intuitions of the subjects were similar to those reported by subjects in the person-naming experiments: the picture cue was thought to be ineffective and the initials cue to be an aid.

\section{GENERAL DISCUSSION}

The data from these three experiments suggest that in TOTSs subjects have accessed the semantic store with the information about the target object, and that only informa- 
tion specifically about the name can aid recall of the name of the target. With reference to the issue of a single versus multiple semantic stores, the experiments suggest that there is a single store for item-specific information (viz., V. Bruce and Young's [1986] PINs), because providing a second route that might have accessed a different information store did not reliably help naming performance.

The headed record framework is not supported by the results here. It would reasonably be expected that a transitory inability to access a record containing a particular person's name from person-specific information in one modality would be relieved by person-specific information presented in a different modality. Such was not the case in these experiments, nor indeed with the converse order of modality presentation in Hanley and Cowell (1988).

We wish to draw three conclusions from this study: First, the absence of facilitation from a different modality in a TOTS-resolving paradigm cue suggests that semantic stores for proper nouns are unitary, and that there are no direct links from perceptual classification (e.g., V. Bruce and Young's [1986] FRU's) to naming output (cf. Nelson et al., 1977). Moreover, the analogy between the processing of faces and that of objects has been further strengthened by the similar patterns of data obtained in Experiments 2 and 3. Finally, we suggest that in TOTSs, only information specifically about the name can facilitate its retrieval. This is nontrivial, because it means that information that uniquely specifies a target (e.g., a picture of it or a semantic description of it), will not resolve TOTSs, and that the initial letter(s) of the target, which may not specify it uniquely, will do so.

\section{REFERENCES}

Brown, R., \& MCNEILL, D. (1966). The "tip-of-the-tongue" phenomenon. Journal of Verbal Learning \& Verbal Behavior, 5, 325-337.

BRUCE, V., \& Young, A. (1986). Understanding face recognition. British Jourmal of Psychology, 77, 305-327.

Cohen, G. Faulkner, D. (1986). Memory for proper names: Age differences in retrieval. British Journal of Developmental Psychology, 4, 187-197.

HaNLEY, J. R., Cowell, E. S. (1988). The effects of different types of retrieval cues on the recall of names of famous faces. Memory \& Cognition, 16, 545-555.

HAY, D. C., \& YounG, A. W. (1982). The human face. In A. W. Ellis (Ed.), Normality and pathology in cognitive functions (pp. 173-202). London: Academic Press.

JAMES, W. (1893). The principles of psychology (Vol. 1). New York: Holt.

JoNEs, G. V. (1989). Back to Woodworth: Role of interlopers in the tip-of-the-tongue phenomenon. Memory \& Cognition, 17, 69-76.

Morton, J., Hammersley, R. H., Bekerian, D. A. (1985). Headed records: A model for memory and its failures. Cognition, 20, 1-23.

Nelson, D. L., Reed, V. S., \& McEvoy, C. L. (1977). Learning to order pictures and words: $A$ model of sensory and semantic encoding. Joumal of Experimental Psychology: Human Leaming \& Memory, $3,485-497$

Ratcliffe, G., \& Newcombe, F. (1982). Object recognition: Some deductions from the clinical evidence. In A. W. Ellis (Ed.), Normality and pathology in cognitive functions (pp. 147-171). London: Academic Press.
ReAD, J. D., \& BruCe, D. (1982). Longitudinal tracking of difficult memory retrievals. Cognitive Psychology, 14, 280-300.

Reason, J. T., Lucas, D. (1984). Using cognitive diaries to investigate naturally occurring memory blocks. In J. Harris \& P. E. Morris (Eds.), Everyday memory, actions and absent mindedness (pp. 5370). London: Academic Press.

Shallice, T. (1988). Specialisation within the semantic system. Cognitive Neuropsychology, 5, 133-142.

YARMEY, A. D. (1973). I recognise your face but I can't remember your name: Further evidence on the tip-of-the-tongue phenomenon. Memory \& Cognition, 1, 287-290.

Young, A., HAY, D., Elus, A. (1985). The faces that launched a thousand slips: Everyday difficulties and errors in recognising people. British Journal of Psychology, 76, 495-523.

Young, A., McWeEnY, K., Ellis, A., HAY, D. (1986). Naming and categorising faces and written names. Quarterly Joumal of Experimental Psychology, 38A, 297-318.

Young, A., McWeeny, K., Hay, D., Ellis, A. (1986). Access to identity-specific semantic codes from familiar faces. Quarterly Journal of Experimental Psychology, 38A, 271-295.

\section{APPENDIX A \\ The 23 Clues Used Exclusively in Experiment 1}

Who has been the bastion of the BBC Holiday program since 1967? (Cliff Michelmore)

Who is the actor who played "The Bionic Man"? (Lee Majors) Who played Purdey in The Avengers? (Joanna Lumley)

This actress was married to Bobby Ewing. (Victoria Principal) Actor whose most famous role was John Steed in The New Avengers. (Patrick MacNee)

This actor is best known as Captain James T. Kirk. (William Shatner)

Who is the male impersonator famous for his impressions of Harold Wilson and Robin Day? (Mike Yarwood)

Which actress was in Upstairs, Downstairs and starred in Telford's Change? (Hannah Gordon)

What goon is found at "Potty Time"? (Michael Bentine)

Who is known from That's Life and In at the Deep End, and now presents the BBC's Windmill? (Chris Serle)

Who is the compere of "Mr. and Mrs."? (Derek Batey)

Who played the brother of Terry and the husband of Thelma in The Likely Lads? (Rodney Bewes)

A London comedian who used to be partnered by his brother, but now partnered by his dog, Schnorbitz. (Bernie Winters)

Who is the Liverpudlian stand-up comic who is obsessed by the Germans? (Stan Boardman)

This man is ITV's foremost football commentator and the host of Who's the Greatest. (Brian Moore)

Who is the cricket-mad TV chat show host who recently took over Desert Island Discs? (Michael Parkinson)

Name the comic actor who was the star of such shows as Selwyn Froggit and The Gaffer. (Bill Maynard)

Who was famous on TV for his red book? (Eammon Andrews)

She starred in a TV series as an agony aunt and is married to Jack Rosenthal. (Maureen Lipman)

Which actor played the role of The Invisible Man in the TV series? (David McCallum)

Name the brace-twanging half of the Northern TV comedy duo. (Bobby Ball)

Who left Coronation Street amid rumors of a pending court case? (Peter Adamson)

Who was the original host of Give us a Clue? (Michael Aspel) 


\section{APPENDIX B}

The 27 Clues Common to Experiments 1 and 2

In a Disney film, who was the musical governess of the Von Trapp children? (Julie Andrews)

Who was the Doctor Who who wore long scarves and ate jelly babies? (Tom Baker)

Which actor plays Arfur Daley's Minder? (Denis Waterman)

This deaf comedian starred in a sitcom with Hattie Jacques playing his sister. (Eric Sykes)

You might find this male comedian in films like $U p$ the Font or Up Pompeii. (Frankie Howard)

He played Richard de Vere, the man who was not quite "To the Manor Born" and only appeared in Only When I Laugh. (Peter Bowles)

Who is the male star of the coffee adverts also starring Sarah Greene? (Gareth Hunt)

Who played the Jackal in the Day of the Jackal? (Edward Fox)

Who played Sebastian Flyte in Brideshead Revisited? (Anthony Andrews)

Who is the Virgin Soldier that starred as the layabout in the TV sitcom Shelley? (Hywel Bennett)

Who plays Del-boy in Only Fools and Horses, and Granville in Open All Hours? (David Jason)

Which actor plays a Dallas oil baron, and also dreams of Jeannie? (Larry Hagman)

Who played Basil Fawlty's Spanish waiter, Manuel? (Andrew Sachs)

This British comedienne is married to Terry in a long-running BBC sitcom. (June Whitfield)

Which actress has a Gentle Touch in The Police Force? (Jill Gascoine)

This Liverpudlian comedian presented Sunday Night Live from the London Palladium. (Jimmy Tarbuck)

Who played Hawkeye, the nurse-chasing, rebellious surgeon in $M^{*} A^{*} S^{*} H$ ? (Alan Alda)

This pink-bowtied Englishman is a captain of a quiz team in Call My Bluff. (Frank Muir)

Who is the male presenter on Crimewatch UK? (Nick Ross)

Who was the TV newsreader who went on to present Live from the Proms, and also has a Radio 3 classical music program? (Richard Baker)

Which actor was the butler in Upstairs, Downstairs, and also organised CI5 in The Professionals? (Gordon Jackson)

Which comic actor plays the miserly grocer Arkwright in the sitcom Open All Hours, and starred also as a Welsh photographer? (Ronnie Barker)

Who played the Italian partner of Hutch in the American cops and robbers series? (Paul Michael Glaser)

Which horn-rimmed bespectacled BBC journalist wouldn't leave home without a certain credit card I could mention? (Alan Whicker)

Who is the female star in Just Good Friends? (Jan Francis)

Which actor starred in The Whistleblower, The Charmer, and was a doctor in Don't Wait Up? (Nigel Havers)

Name the comedian who played a scatty executive in The Rise and Fall of Reginald Perrin. (Leonard Rossiter)

\section{APPENDIX C}

The 23 Clues Used Exclusively in Experiment 2

This verbose Londoner is famous for appearances in Carry On films and on Radio 4's Just a Minute program. (Kenneth Williams)
This American actress starred opposite Woody Allen in Annie Hall and Sleeper. (Diane Keaton)

A macho international film star also famous for his prowess at the game of bridge. (Omar Sharif)

Glamorous American actress renowned for having the longest dream in TV soap history, and for a screen husband who takes very long showers. (Victoria Principal)

The nervous man with the knife, in the shower scene in Hitchcock's Psycho. (Anthony Perkins)

Played George, the wimpy, hen-pecked husband of Mildred in a long-running 1970's sitcom. (Brian Murphy)

The man who, with Jack Lemmon, made an "Odd Couple," and who once stayed in a "California Suite." (Walter Matthau)

She was the "French Lieutenant's Woman" and also starred in Kramer vs. Kramer. (Meryl Streep)

Who was the female star of Moonlighting? (Cybill Shepherd)

The American male star of Scarface who also starred in The Godfather. (Al Pacino)

The star of the Oscar-winning film Gandhi. (Ben Kingsley)

This comic actor was crazy about "A Woman in Red." (Gene Wilder)

This guy spent his "Happy Days" as The Fonz. (Henry Winkler)

Singer and actress, she had a hit with Woman in Love and a film hit with Yentl. (Barbra Streisand)

Who plays private eye Magnum? (Tom Selleck)

This actor is the most famous Count Dracula in the Hammer Horror films. (Christopher Lee)

He starred in Some Like it Hot alongside Marilyn Monroe and in The Apartment alongside Shirley MacLaine. (Jack Lemmon)

This man played the bowler-hatted Secret Service agent in The Avengers and The New Avengers. (Patrick MacNee)

This legendary male entertainer was "Singing in the Rain" in 1952, and also starred in Xanadu in 1980. (Gene Kelly)

Who plays Blake Carrington in Dynasty? (John Forsythe)

Revered British actor who played the British captain in Bridge over the River Kwai, Ben Kenobi in Star Wars, and appeared in Smiley's People. (Alec Guinness)

Starred in Ben Hur and Planet of the Apes; now plays Sabel's husband in The Colbys. (Charlton Heston)

Starred as Sergeant Wilson in Dad's Army, opposite Arthur Lowe, and died in 1984. (John Le Mesurier)

\section{APPENDIX D}

\section{The 40 Landmark Clues Used in Experiment 3}

This is an ancient Roman ruin in modern day Rome, where gladiators used to fight the Christians. (Colosseum)

A famous ancient temple overlooking Athens. (Parthenon)

The imposing hill overlooking Athens. (Acropolis)

The world's largest single rock, in the middle of the Australian outback. (Ayers Rock)

A fountain in Rome where throwing a coin into the water is supposed to ensure that you return to Rome later in life. (Trevi Fountain)

A famous flight of steps in Rome. (Spanish Steps)

Florence's most famous statue, sculpted by Michelangelo. (Statue of David)

New York skyscraper which used to be the tallest building in the world. (Empire State Building)

The stretch of river in Istanbul, which forms the straits between Europe and Asia. (Bosphorus straits)

The central piazza in Venice. (St. Mark's Square) 
Bristol's high bridge from which daring stunts are sometimes tried. (Clifton Suspension Bridge)

The world's largest archway, which is in Paris. (Arc de Triomphe)

The large metallic structure in Paris. (Eiffel Tower)

Legend has it that Rome was founded by two boys who were deserted by their parents, and were brought up by a wolf. They form the symbol of the city of Rome-what are they called? (Romulus and Remus)

The bridge that spans San Francisco Bay. (Golden Gate Bridge)

The Florence bridge which is famous for its elegant shops. (Ponte Vecchio)

The mountain outside Cape Town, South Africa with a distinctive top. (Table Mountain)

The most famous mountain in the Alps, with a distinctive peak. (The Matterhorn)

The most famous idyllic palace in India. (Taj Mahal)

The bridge in Venice which is known for being colourfully decorated. (Rialto Bridge)

In the heart of Copenhagen lies a world famous fun fair, with flower gardens and firework displays. (Tivoli Gardens)

There is a mountainside in the Rockies mountain range in North America which has been sculpted. (Mount Rushmore)

The marble building in Italy which will fall over by the year 2020, it is said. (Leaning Tower of Pisa)

The building where the USA Congress meets. (Capitol building)

The famous drawbridge in London. (Tower Bridge)

In Arizona there is a large and spectacular scar in the earth. (Grand Canyon)
The London cathedral designed by Sir Christopher Wren. (St. Paul's Cathedral)

The thunderous waterfall in North America. (Niagara Falls)

Dublin's premier university college, which was used to film Educating Rita. (Trinity College)

The ancient wall built by the Romans at the northern border of their empire, in order to keep out the Scots. (Hadrian's Wall)

An enormous length of fabric woven by the French to commemorate the Battle of Hastings. (Bayeux Tapestry)

In Bath there is a row of houses which is deemed to be a superb example of Georgian architecture. (Royal Crescent)

The main law court in London. (Old Bailey)

The huge area in front of the Kremlin. (Red Square)

In Brighton there is an ornamental palace built in the eighteenth century, which has strong Eastern connections. (Royal Pavilion)

The obelisk in the middle of Trafalgar Square. (Nelson's Column)

The symbol of the city of Brussels is a mischievous little boy. (Mannekin Pis)

The large monument at the entrance to New York harbour. (Statue of Liberty)

The ancient rocks on Salisbury Plain. (Stonehenge)

In Ireland there is a famous piece of rock that brings good luck to those who kiss it. (Blarney Stone)

(Manuscript received July 18, 1988; revision accepted for publication September 19, 1989.) 